\title{
Design and development of novel bioreactor for the production of ethanol from low cost pretreated rice straw
}

\author{
V. Sindhu ${ }^{1}$, C.N. Kanchana, N.S.Vasanthi, R.Ravikumar ${ }^{1 *}$ \\ ${ }^{I}$ Department of Biotechnology, Bannari Amman Institute of Technology, Sathyamangalam, \\ Erode District - 638 401, TamilNadu, India.
}

\begin{abstract}
Lignocellulosic biomass is a renewable, abundant resource and its utilization for producing valuable products like ethanol, enables intensified simultaneous product formation and solid waste management. A laboratory horizontal rotating biological reactor was designed and fabricated for ethanol production using low cost pretreated rice straw by Saccharomyces cerevisae. The bioreactor was operated at $38^{\circ} \mathrm{C}$ using rice straw as carbon source, at $70 \%$ moisture content. High levels of cellulolytic and hemicellulolytic activities were obtained. The overall performance of the bioreactor was promising for further investigation. The yield of ethanol obtained in the designed reactor is 1.5 times greater than conventional one. SEM analysis was carried out to confirm the structural transformation taking place during the fermentation process. GC/MS analysis was carried out for the estimation of ethanol content.
\end{abstract}

Keywords: Lignocellulose, Pretreatment, Pleurotus Sp, Rice straw, Ethanol

\section{INTRODUCTION}

Ethanol production through biotechnological has acquired considerable interest due to possible utilization of bio-ethanol as an alternative fuel. The rise in prices and environmental problems caused by fossil fuels has contributed to this recent interest from economical and ecological perspectives (Shiva et al., 2012; Yamshita et al., 2008). Rice straw is one of the abundant lignocellulosic waste materials in the world. Rice straw is a by-product of rice production and a great bioresource (Nutawan et al., 2010). An ideal pretreatment is needed to reduce the lignin content and crystallinity of the cellulose, and increase the surface area of these materials. To enhance susceptibility to enzymatic hydrolysis and digestability, or the nutritive value of different lignocellulases, various pretreatments using white-rot fungi have been examined (Pan et al., 2005) A direct and efficient ethanol production process was obtained from high-yielding rice harvested in Japan by using amylase expressing yeast without any pretreatment or addition of enzymes or nutrients. Ethanol productivity from high yielding brown rice $(1.1 \mathrm{~g} / \mathrm{L} / \mathrm{h})$ was about 5 -fold higher than that obtained from purified raw corn starch $(0.2$ $\mathrm{g} / \mathrm{L} / \mathrm{h}$ ) when nutrients were added. Using an inoculum volume equivalent to $10 \%$ of the fermentation volume without any nutrient supplementation resulted in ethanol productivity and yield reaching $1.2 \mathrm{~g} / \mathrm{L} / \mathrm{h}$ and $101 \%$, respectively, in a 24-h period (Ryosuke et al. 2011).Many different kinds of bioreactors have been used in solid state fermentation, which uses quantities of dry solid medium from a few grams up to a few klilograms (Brand et al 2010). Several bioreactors like tray reactor, packedbed reactor were used for the production of ethanol using wheat straw and starch with Aspergillus niger and Bacillus sp. The present work is focused on design of Rotating Biological Reactor (RBR) with optimum critical speed. In addition, design was also focused on the baffles, and jacketed vessel.

\subsection{Materials:}

\section{MATERIALS AND METHODS}

Rice straw used in the present study was collected from the paddy fields in Sathyamangalam, Erode District, TamilNadu.. The rice straw collected from the paddy field was soaked in sufficient quantity of water for a period of 6- 8 hours and autoclaved at 30psi for 1 hour. The autoclaved rice straw was further air dried, pretreated using Pleurotus ostreatus and used. The instruments used in the present study are UV Spectophotometer (Perkin Elmer Lambda 35, Singapore), Scanning Electron Microscopy (SEM) (JEOL 6390, JAPAN), Electronic balance (Mettler Teledo AB 265-S) and Gas Chromatography - Mass Spectrometry (THERMO GC- TRACE ULTRA VER: 5.0, THERMO MS DSQ II)

\subsection{Design of Rotating Biological Reactor (RBR):}

Existing vertical bioreactor used for solid state fermentation with agitator creates shear stress to the substrate and depletes the rate of mass transfer and heat transfer. The mixing index for substrate and inoculum is very less. This inturn reduces the yield and conversion of substrate to ethanol. The surface area for the biochemical reaction to take place is less in the existing reactor. In the present study reactor is placed in horizontal position with less head space which increases the specific surface area for substrate and organism to 
react. It offers effective mass transfer and reduces the reaction time than conventional. Most of the industries uses reactor and distillation column separately which makes the continuous process time consuming. The moisture content is maintained by sparging of water from peristaltic pump so that uniform moisture content is maintained throughout the substrate The overall design of the reactor aims at enhancing the diffusion and overcome the mass transfer limitations. In order to overcome the drawback in the existing design of the bioreactor a novel approach was formulated. The concept of ball mill is being used. The centrifugal force of the reactor was equated to substrate weight and hence the critical speed of the reactor was fixed.

$$
N c=\frac{1}{2 \Pi} \sqrt{\frac{g}{R-r}}
$$
the particle.

Where $\mathrm{Nc}$ is the critical speed of the bioreactor, $\mathrm{R}$ is the radius of the bioreactor and $\mathrm{r}$ is the radius of

\subsection{Solid state fermentation :}

Batch experiment was carried out in the designed and fabricated Rotating Biological Reactor (RBR).The glucose obtained through enzymatic hydrolysis by commercial cellulase enzyme was fermented into ethanol using baker's yeast (Saccharomyces cerevisiae). The inoculum was prepared by weighing $15 \mathrm{~g}$ of baker's yeast and mixing it with $50 \mathrm{ml}$ of distilled water. It was further boiled to revive the yeast culture. Once revived, it was directly used as inoculum. They were maintained at varying $\mathrm{pH} 4$, temperature $35^{\circ} \mathrm{C}$, substrate concentration $5 \mathrm{~g}$ of rice straw, inoculum concentration $5 \mathrm{ml}$ of baker's yeast, time of fermentation 3days, agitation 300rpm. The moisture content ws maintained at $70 \%$. The $\mathrm{pH}$ was maintained using Citrate buffer . After the completion of the fermentation process, ethanol was separated from the fermentation broth by simple distillation. Initially, the fermented medium was filtered. The residue was discarded and the filtrate was further centrifuged to remove the yeast cells in the form of pellet. The supernatant obtained was further distilled at $78^{\circ} \mathrm{C}$ using a simple distillation apparatus. The volume of the supernatant and the volume of the distillate obtained were noted. The ethanol concentration in the distillate was analysed.

\subsection{Estimation of ethanol content :}

The ethanol content was estimated for the distillates obtained by Chromic Acid assay (Gattas et al., 2003) The Gas Chromatographic analysis of ethanol content (Liu and Shen, 2008; Weixing, et al., 2012) was carried out for absolute The concentration of the test samples were calculated using the formula, $\backslash$

$$
\text { Concentration.of .the.test.sample }(\%)=\frac{\text { Test.area }}{S \tan \text { dard.area }} x 100
$$

\subsection{GC/MS Analysis :}

Ethanol was analyzed using GC-MS (Gas Chromatography - Mass Spectrometry) (THERMO GCTRACE ULTRA VER: 5.0, THERMO MS DSQ II) equipped with Capillary Standard non-polar column (DB $35-\mathrm{MS}$ ) of $30 \mathrm{~m}$ height, internal diameter $0.25 \mathrm{~mm}$ and film thickness $0.25 \mu \mathrm{m}$. One microliter of extract was injected to analyse by GC-MS at preset conditions. The carrier gas used was He with flow rate of $1.0 \mathrm{~mL} / \mathrm{min}$. The temperature program was set such as the initial oven temperature was $40^{\circ} \mathrm{C}$ which was further raised to $270^{\circ} \mathrm{C}$ at a rate of $8^{\circ} \mathrm{C} / \mathrm{min}$.

\section{RESULTS AND DISCUSSION}

\subsection{SEM Analysis of the pretreated rice straw :}

SEM analysis were performed for various samples of rice straw treated with Pleurotus sp. at different conditions. (Fig:1). 
Design and development of novel bioreactor for the production of ethanol from low cost pretreated rice straw

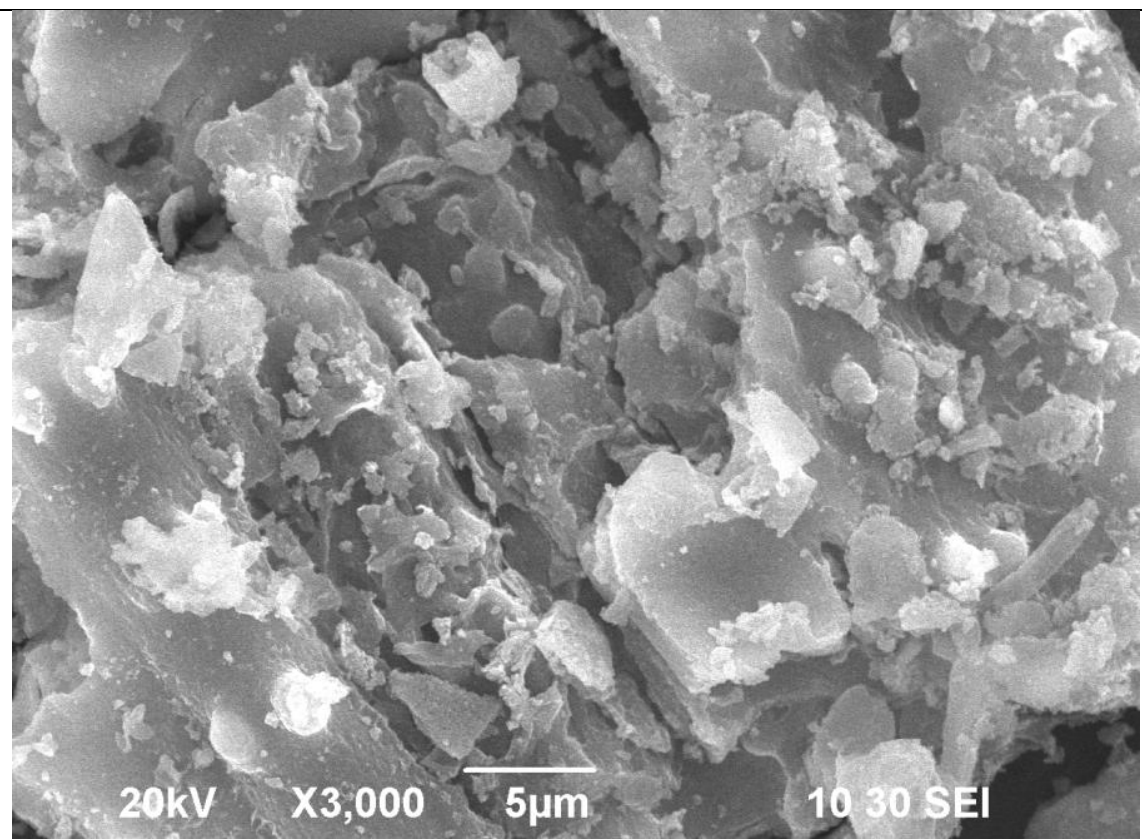

Fig.1. SEM images: Rice straw treated with Pleurotus ostreatus

The SEM images indicated that rice straw treated with Pleurotus florida showed relatively intact structure when compared to that of the rice straw untreated The rice straw treated with Pleurotus florida seemed to be lengthy and streak in nature thus creating particles with large surface area. Similar results were obtained on treatment of rice straw with hot- compressed water (HCW) and dry ball mill treatment (Akihiro et al., (2009). In a similar study during SEM analysis clear cellulose microfibrils and lignin globules were not observed in milled rice straw particles, the appearance of globules, which are characteristic of lignin deposition around the cellulose layer, was evident in acid-treated rice straw (Harinder et al., 2010). This proves that treatment of rice straw by biological means degrades the lignin and reduces the crystallinity of cellulose fraction.

\subsection{Design parameters of Rotating Biological Reactor :}

The Rotating Biological Reactor designed and fabricated was shown in Fig :2 with the pretreated rice straw. The design parameters of the reactor was shown in Table :1 This novel bioreactor increased the efficiency of the ethanol production than the conventional reactors. This is due to the increase in the rate of diffusion and the heat transfer effect. Since the reactor is maintained in the critical speed it enhances the efficiency of the production.

\section{Table: 1 Equipment Design Parameters}

\begin{tabular}{|c|c|}
\hline Specification of the bioreactor & Design Dimensions \\
\hline Diameter of the reactor (Da) & $3 \mathrm{~cm}$ \\
\hline Height of the reactor(h) & $19 \mathrm{~cm}$ \\
\hline Height of the reactor(h) & $19 \mathrm{~cm}$ \\
\hline Diameter of the jacketed vessel (d) & $9 \mathrm{~cm}$ \\
\hline Height of the jacketed vessel (ha) & $19 \mathrm{~cm}$ \\
\hline Diameter of the baffle (da) & $3 \mathrm{~cm}$ \\
\hline Height of the baffle(h) & $6 \mathrm{~cm}$ \\
\hline Orifice diameters(d1 d2 d3) & $0.02,0.04,0.06 \mathrm{~cm}$ \\
\hline Critical speed of the reactor & $68.75 \mathrm{rpm}$ \\
\hline Air flow rate & $2.0 \mathrm{vvm}$ \\
\hline Aspect ratio & 2.1 \\
\hline Temperature & $37 \mathrm{c}$ \\
\hline pH & 4.4 \\
\hline Moisture content & $70 \%$ \\
\hline Height of the reactor(h) & $19 \mathrm{~cm}$ \\
\hline Diameter of the jacketed vessel (d) & $9 \mathrm{~cm}$ \\
\hline Height of the jacketed vessel (ha) & $19 \mathrm{~cm}$ \\
\hline
\end{tabular}


Design and development of novel bioreactor for the production of ethanol from low cost pretreated rice straw
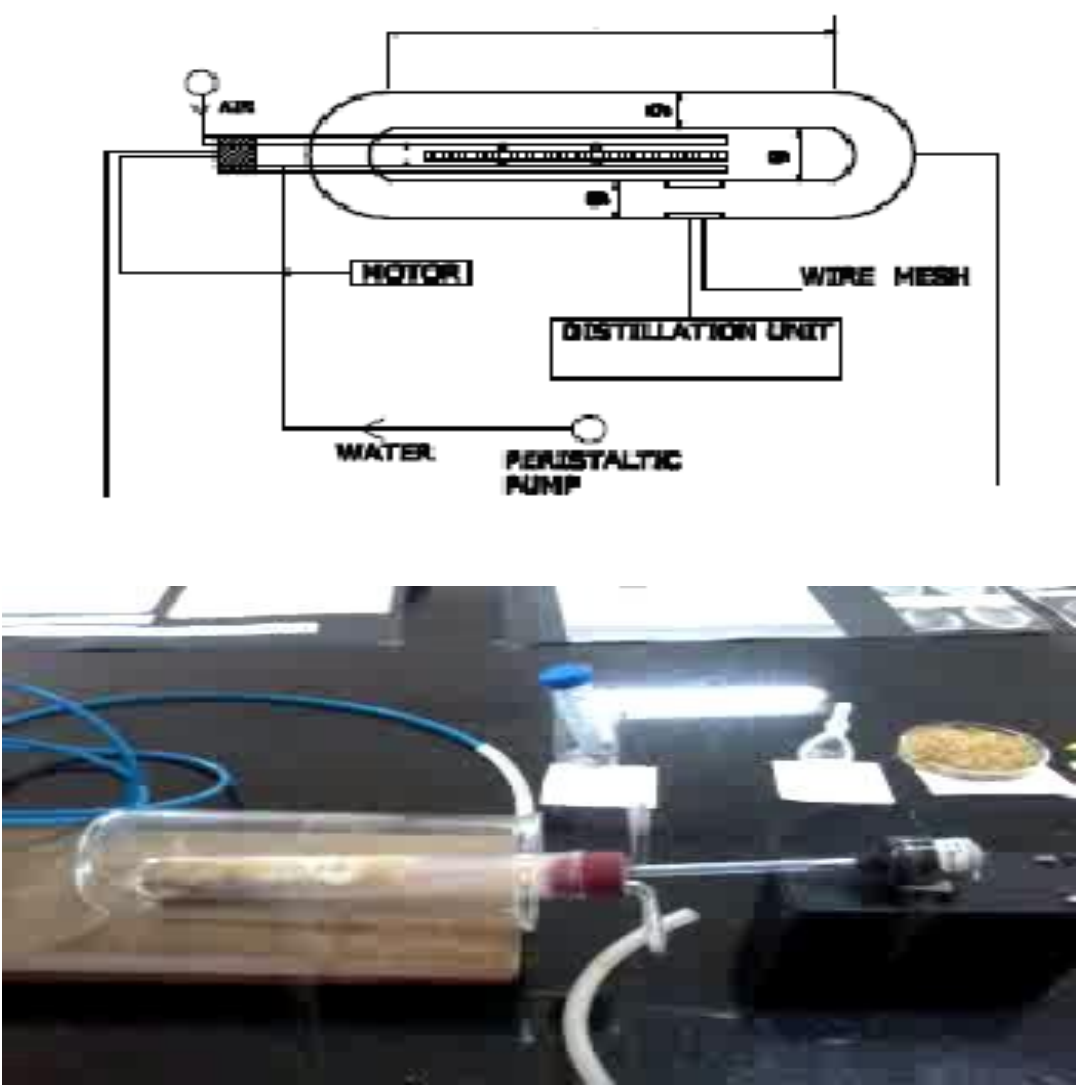

Fig: 2 (a)Rotating Biological Reactor (RBR) design represented in CAD (b)Rotating Biological Reactor (RBR with rice straw

\subsection{GC-MS analysis for the estimation of ethanol production :}

The chromatogram for absolute ethanol shows a steep peak with the retention time of $2.582 \mathrm{~min}$, and $\%$ areas of 229635 respectively (Figure 3). The concentration of ethanol was calculated based on the above equation[Eqn.(1)] and was found to be $0.14 \%$. This ensures effective mixing and diffusion has taken place during the fermentation process in the RBR. The rate is enhanced and effective substrate utilsation is achieved

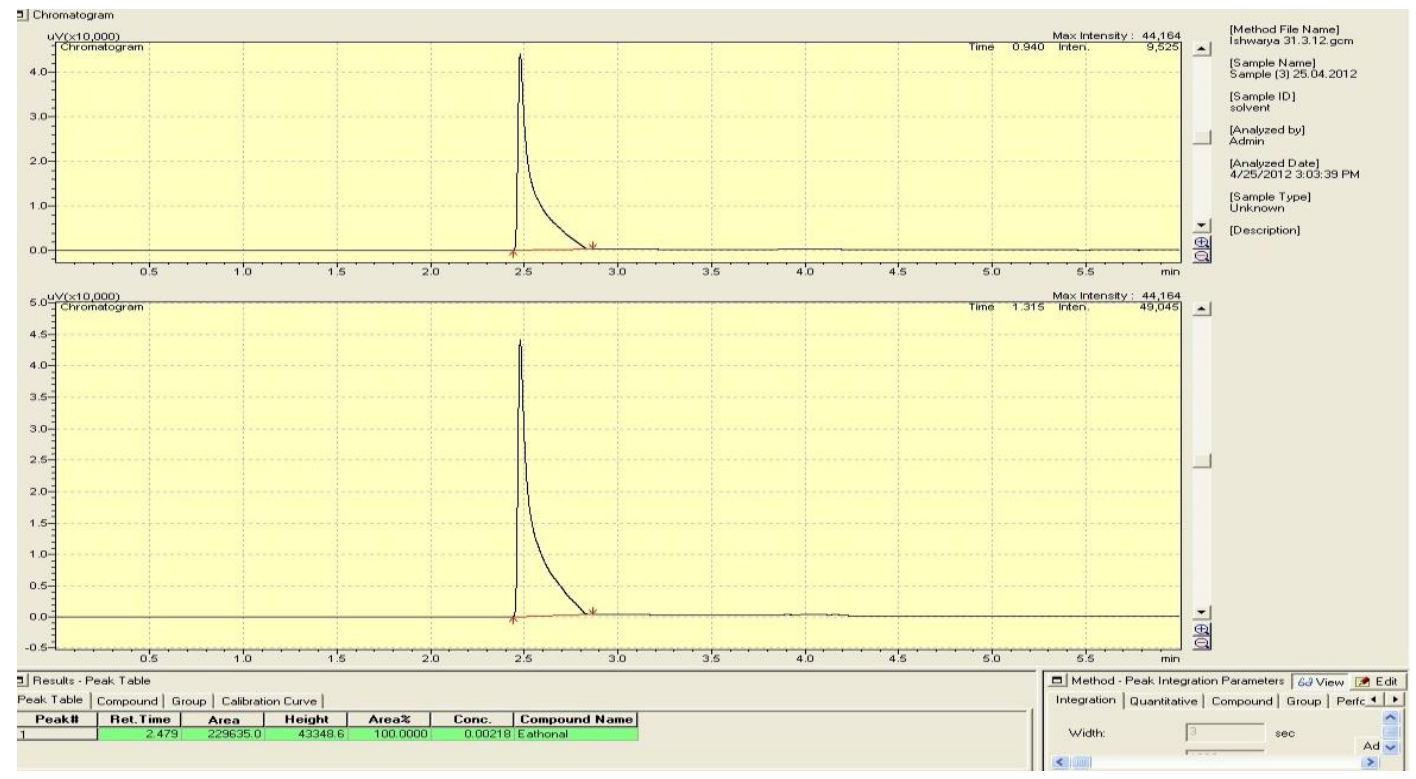

Fig 3: GC analysis for (a) Absolute ethanol (b) test sample 


\section{CONCLUSIONS}

The demand for fuel intensed the researchers to search on sources for the production of an alternative fuel. It also emphasized the effective conversion of sources to ethanol. The lignin was effectively degraded using the white rot fungus, Pleurotus ostreatus. The novel design of the Rotating Biological Reactor has increased the ethanol production and proved to be a best reactor than the conventional reactors.

\section{ACKNOWLEDGEMENTS}

Authors thank the Management of Bannari Amman Institute of Technology, Sathyamangalam, for the constant support. We thank Villgrow/IIT Madras/ PSG - STP, BIT for providing the fund to carry out our research. We also thank the management of Karunya University, Coimbatore, Tamil Nadu, India for helping in SEM analysis .

\section{REFERENCE}

1. Shiva, S., Mohammad, F.G. and Soheil, S. (2012) 'Ethanol production by Zymomonas mobilis PTCC 1718 using low cost substrates', African Journal of Microbiology Research Vol.6, No.4, pp.704-712.

2. Yamshita, Y., Kurosumi, A., Sasaki, C. and Nakamura, Y. (2008) 'Ethanol production from paper sludge by immobilized Zymomonas mobilis', Journal of Biochemical Engineering Vol.42, pp.314-319.

3. Nutawan, Y., Phattayawadee, P., Pattranit, T. and Mohammad, N.E. (2010) 'Bioethanol production from rice straw', Energy Research Journal Vol.1, No.1, pp.26-31.

4. Pan, X., Arato, C., Gilkes, N., Gregg, D., Mabee, W., Pye, K., Xiao, Z., Zhang, X. and Saddler, J. (2005) 'Biorefining of soft woods using ethanol organosolv pulping: preliminary evaluation of process streams for manufacture of fuel-grade ethanol and co-products', Biotechnology Bioengineering Vol.90, pp.473-481.

5. Ryosuke, Y., Syun-ichi, Y., Tsutomu, T., Chiaki, O., Hideki, F. and Akihiko, K. (2011) 'Direct and efficient ethanol production from high-yielding rice using a Saccharomyces cerevisiae strain that express amylases', Enzyme and Microbial Technology Vol.48, pp.393396.

6. Brand, D., Soccol, C. R., Sabu, A., Roussos, S., Production of fungal biological control agents through solid state fermentation : Case study on Paecilomyces Lilacinus against root knot Nematodes . Micro. Appl. Int. 22 (2010) 31.

7. Liu, R. and Shen, F. (2008) 'Impacts of main factors on bioethanol fermentation from stalk juice of sweet sorghum by immobilized Saccharomyces cerevisiae (CICC1308)', Bioresource Technology Vol.99, pp.847-854.

8. Weixing, C., Chen, S., Ronghou, L., Renzhan, Y. and Xiaowu, W. (2012) 'Comparison of the effects of five pretreatment methods on enhancing the enzymatic digestibility and ethanol production from sweet sorghum bagasse', Bioresource Technology Vol.111, pp.215221 .

9. Akihiro, H., Hiroyuki, I., Kenichiro, T., Shinji, F., Tomoaki, M., Seiichi, I., Takashi, E. and Shigeki, S. (2009) 'Wet disk milling pretreatment without sulphuric acid for enzymatic hydrolysis of rice straw', Bioresource Technology Vol.100, pp.2706-2711.

10. Harinder, S.O., Praveen, V.V., Khushal, B., Vinod, K.B. and Ramabhau, T.P. (2010) 'Enhanced ethanol producrion via fermentation of rice straw with hydrolysate- adapted Candida tropicalis ATCC 13803', Process Biochemistry Vol.45, pp.1299-1306. 